\title{
Knowledge and Practice of ICU Nurses Regarding Endotracheal Suctioning in Tertiary Care Hospitals, Peshawar
}

\author{
Aurang Zeb*, Shams-ul-Haq, Farhad Ali, Nazia Hussain, Syed Haidar Ali Shah and Shah Faisal \\ Rehman College of Nursing, Pakistan
}

Submission: June 09, 2017; Published: July 06, 2017

*Corresponding author: Aurang Zeb, Rehman College of Nursing, Pakistan, Email: aurang.zeb@rmi.edu.pk

\begin{abstract}
Objectives: To explore the knowledge and practice of the ICU nurses regarding endotracheal suctioning.

Method: A descriptive cross sectional study was conducted among ICU nurses regarding knowledge and practice of endotracheal suctioning in Tertiary care private and public sector hospitals of Peshawar. Participants were selected through convenient sampling technique. A well-structured questionnaire was used for data collection. The autonomy and confidentiality was assured through a well-defined informed consent.
\end{abstract}

Result: A total of 65 nurses were included in the study from ICU of four Tertiary care Hospitals of Peshawar. 29.2\% were male participants and $70.8 \%$ were female. The mean knowledge of the participants regarding ETT suctioning was $50.04 \% \pm 18.963 \%$, while the mean Practice level was $80.37 \% \pm 18.37 \%$. Gender had significant relation with knowledge and practice regarding endotracheal suctioning with p-value 0.043 .

Conclusion: The study identified that nurses working in ICUs of Tertiary care hospitals in the region have average knowledge of ET suctioning, though their practice was good. Still there is need of policies for improving nurses' knowledge and practice regarding ET suctioning.

\section{Introduction}

Endotracheal suctioning (ETS) is the removal of secretion from tracheobronchial tree through the endotracheal tube with the help of mechanical suction device to maintain the patient airway and to prevent the respiratory tract infection because of lodgment of secretion. It is a common procedure which is performed by intensive care nurses for the purpose of establishing and maintaining gas exchange, adequate oxygenation and alveolar ventilation in critically ill mechanical ventilated patients [1]. Nurse's knowledge and compliance to proper suctioning techniques are very important for prevention of infections. Different studies suggest different knowledge and compliance of nurses regarding ETT suctioning.

Research shows that nurses are unaware of current suctioning recommendations and their practice is often based on ritual and tradition techniques as opposed to empirical evidence [2]. In 2010 the American association of respiratory care (AARC) published the AARC clinical guidelines on endotracheal tube suctioning of mechanically ventilated patients with artificial airway, which is based on 10 guidelines recommendations.
However; only some of studies showed that the guidelines for endotracheal suctioning are known and correctly followed by ICU nurses [1]. Day and collaborators in the UK conducted the most important research on the topic. They described that nurses are often not aware of the existence guideline, Moreover; they found that there is a big discrepancy between guideline and nursing practice, where the nurses did not followed the evidence based practices [1,3].

Improper techniques may cause complications, ranging from trauma and hypoxemia to, in extreme cases, cardiac arrest, and death. It is imperative that nurses' should be aware of these risks and should be able to Practice according to AARC recommendations [4]. Study shows that the knowledge and practice of nurses regarding ETT suction was poor, with no significant relationship between the two [3]. Participants of a study did not follow the recommended guidelines for practices and consequently provided lower-quality endotracheal suctioning. Significant inconsistencies were observed in the participants' respiratory assessment techniques, hyper oxygenation and 
infection control practices, patient reassurance and the level of negative pressure used to clear secretions [5]. A study in two ICUs of a large university hospital in MatoGrossodoSul, Brazil shows that the nurses who have higher degree were better theoretical knowledge than the nursing technicians regarding the endotracheal tube suctioning procedure [6]. Nurses in Khartoum teaching hospital Sudan have a better practical level than knowledge of endotracheal suctioning [7]. Study addressed the level of knowledge on ETT suctioning among staff nurses and student nurses in Narayana Medical College and Hospital India showed that $7 \%$ of staff nurses had inadequate knowledge, $73 \%$ had Moderate knowledge, and $20 \%$ had adequate knowledge. While $20 \%$ of nursing students had inadequate knowledge and $80 \%$ had moderate knowledge [8]. A study [9] at Aga Khan University, Karachi Pakistan addressed the nurse's knowledge regarding the phases of pre, during and post tracheal suctioning practices and its complications concluded that the evidence based practices guidelines were followed by the health care professionals [9]. The current study helps to identify risks related to suctioning among patient in different hospitals of KPK. The health department should make and implement policies regarding knowledge and evidence based practices for nurses.

\section{Methodology}

A descriptive cross sectional study was performed to determine the Knowledge and practice of ICU nurses regarding endotracheal suctioning. The study settings were the medical and surgical ICUs of Tertiary care private and public sectors hospitals of Peshawar, KPK. Convenient sampling technique was used for sample selection from the population of Registered Nurses working in ICUs. Sample size was calculated by Raosoft software, with population size 140 with $5 \%$ of margin of error and $10 \%$ non-responsive rate. The calculated sample size was 70 .

\section{Inclusion criteria}

A. The registered Nurses working in ICU

B. Have more than 6 months experience.

\section{Exclusion criteria}

A. Head Nurses and managerial nurses.

B. Infection control nurses.

A well-structured questionnaire was used for data collection. Questions were adopted and modified from published studies $[4,10]$. For the reliability, the questionnaire was applied on $15 \%$ of the sample size as pilot testing. The autonomy and confidentiality of the participants were assured through a well explained informed consent.

\section{Results}

A total of 65 subjects were included in the study from different Tertiary care Hospitals. $29.2 \%$ were male participants and $70.8 \%$ were female. Mean age of the participants was $27.22 \pm 6.10$ years. The academic education level of the participants was found as: Matric 38.5\%, FSc40\%, BSc 20\%, and MSc 1.5\%. While Professional qualifications of the participants were as; diploma holders $70.8 \%$ and BSN degree holders $29.2 \%$. Mean and standard deviation of nurse patient ratio was $3.72+1.644$. The total professional experience in years is $4.74 \pm 0.732$, while the mean ICU experience is $2.82+2.277$ years respectively (Figure 1 , $2 \& 3)$.

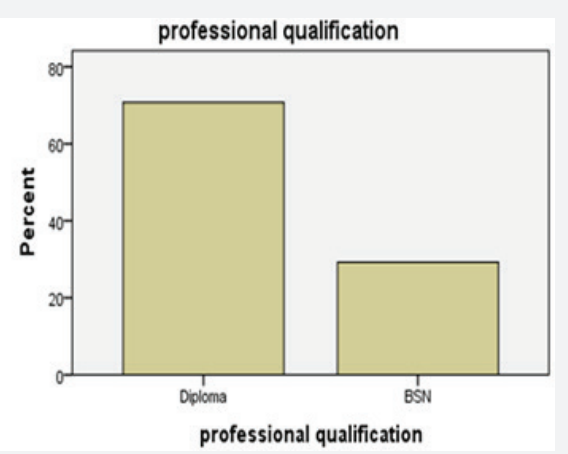

Figure 1: The mean knowledge of the participants regarding ET suctioning was $50.04 \%+18.963 \%$ (chart1.2). Thepractice of the participants was also calculated in percentage, the mean practice was $80.37 \%+18.37 \%$.
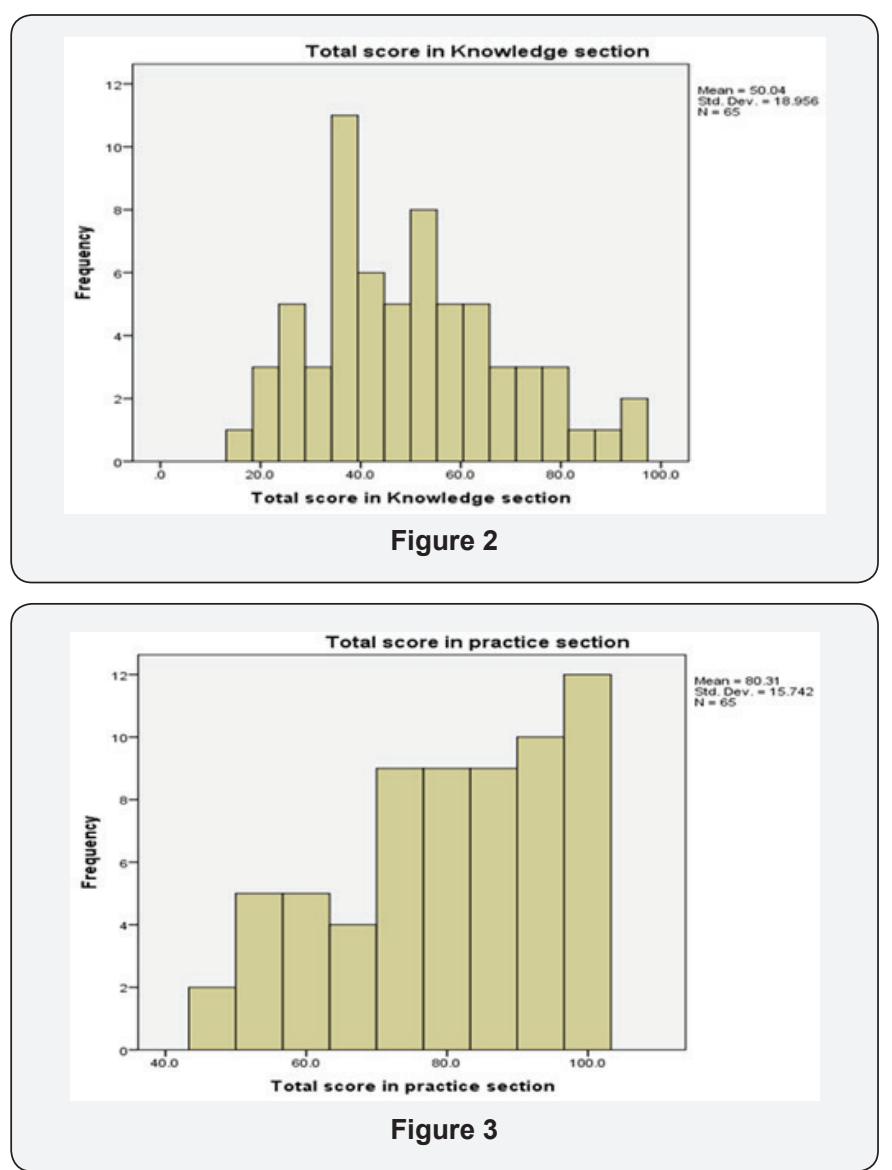

Moreover; Independent Sample $\mathrm{t}$ test was applied for the association of gender with knowledge and practice of ET suctioning, where the association of gender regarding ET suctioning was significant with $P$ value 0.043 . 


\section{Discussion}

The outcome of the study is compared with publishedliterature. A study conducted by Tina Day showed that the knowledge and practice of nurses regarding ETT suction was poor. Another study conducted by shows that nurses were unaware of recommended practice and demonstrated unsafe practice [3]. Nurses working in Narayana Medical College and Hospital India showed that $7 \%$ of staff nurses had inadequate knowledge, 73\% had Moderate knowledge, and 20\% had adequate knowledge [8].Whereas the findings of current study showed a mean knowledge of the participants regarding ET suctioning is $50.04 \% \pm 18.963 \%$ and the mean practice is $80.37 \% \pm 8.37$ (Table 1).

Table 1: The overall response percentage to the practice part of the Questionaire.

\begin{tabular}{|c|c|c|c|}
\hline S. NO & Practise Questionaire Section & Yes & No \\
\hline 1 & $\begin{array}{l}\text { Do you auscultate the patient's } \\
\text { chest before ETT suctioning? }\end{array}$ & $60 \%$ & $40 \%$ \\
\hline 2 & $\begin{array}{l}\text { Do you explain procedure to the } \\
\text { patient? }\end{array}$ & $81.50 \%$ & $18.50 \%$ \\
\hline 3 & $\begin{array}{l}\text { Do you hyper oxygenate the } \\
\text { patient before suctioning? }\end{array}$ & $64.60 \%$ & $35.40 \%$ \\
\hline 4 & $\begin{array}{l}\text { Do you wash hands prior to } \\
\text { suctioning? }\end{array}$ & $95.40 \%$ & $4.60 \%$ \\
\hline 5 & $\begin{array}{l}\text { Do you use Gloves during } \\
\text { suctioning? }\end{array}$ & $93.80 \%$ & $6.20 \%$ \\
\hline 6 & $\begin{array}{c}\text { Do you use Apron during } \\
\text { suctioning? }\end{array}$ & $60.00 \%$ & $40 \%$ \\
\hline 7 & $\begin{array}{l}\text { Do you maintain the sterility of } \\
\text { suction catheter until inserted in } \\
\text { to Airway? }\end{array}$ & $87.70 \%$ & $12.30 \%$ \\
\hline 8 & $\begin{array}{c}\text { Do you use Goggles/Face Mask } \\
\text { during suctioning? }\end{array}$ & $81.50 \%$ & $18.50 \%$ \\
\hline 9 & $\begin{array}{l}\text { Do you use dipose catheter and } \\
\text { gloves in manner that prevents } \\
\text { contamination from secretion? }\end{array}$ & $92.30 \%$ & $7.70 \%$ \\
\hline 10 & $\begin{array}{c}\text { Do you ewant reconnect oxygen } \\
\text { within in } 10 \text { second to the patient } \\
\text { after suctioning }\end{array}$ & $84.60 \%$ & $15.40 \%$ \\
\hline 11 & $\begin{array}{l}\text { Do you wash hands after } \\
\text { suctioning? }\end{array}$ & $89.20 \%$ & $10.80 \%$ \\
\hline 12 & $\begin{array}{l}\text { Do you Lubricates the suction } \\
\text { catheter tip with normal saline? }\end{array}$ & $78.50 \%$ & $21.50 \%$ \\
\hline 13 & $\begin{array}{l}\text { Do you pick up the suction } \\
\text { catheter with the dominant hand } \\
\text { and attach it to the connection } \\
\text { tubing? }\end{array}$ & $83.10 \%$ & $16.90 \%$ \\
\hline 14 & $\begin{array}{l}\text { Do you test the suction equipment } \\
\text { by occluding the connection } \\
\text { tubing? }\end{array}$ & $81.50 \%$ & $18.50 \%$ \\
\hline 15 & $\begin{array}{c}\text { Do you placed towel on the } \\
\text { patient's chest during suctioning? }\end{array}$ & $67.70 \%$ & $32.30 \%$ \\
\hline
\end{tabular}

The practice of Nurses related to ET suctioning working in different part of the world is also important. Nurses working in Khartoum teaching hospital Sudan had a better practice level than knowledge. A on the nurses knowledge regarding the phases of pre, during and post tracheal suctioning practices and its complications in Aga Khan University, Karachi Pakistan, concluded that the evidence based practices guidelines were followed and maintained by the health care professionals and play a vital role in enhancing safety of the patient [9]. Nurses showed appropriate practice patterns such as suctioning patients' mouths, oral care practices, and maintaining the appropriate pressure in the cuff of the endotracheal tube at a set level need to be evaluated to prevent the patient from VAP. As compare the Current study shows a better finding in practice regarding ET suctioning, the mean practice was $80.37 \% \pm 18.37 \%$.

In contrast many studies showed that practices of ETT suction are inadequate and did not follow the standard guidelines. The study by Kelleher \& Andrews identified that participants did not follow recommended guidelines for practices and consequently provided lower-quality endotracheal tube suctioning. Significant 
inconsistencies were observed in the participants' respiratory assessment techniques, hyper oxygenation and infection control practices, patient reassurance and the level of negative pressure used to clear secretions. While the current study shows a better practice of the ICU Nurses regarding ET suctioning working in public and private sector tertiary care hospitals of Peshawar, KPK, Pakistan, where the mean practice level of the participants was $80.37 \% \pm 18.37 \%$. A study conducted by de Oliveira Matias Ferreira shows that the nurses who have higher degree were better theoretical knowledge than the nursing technicians regarding the endotracheal tube suctioning procedure. While in current education was non-significant, by (sample ONE-ANOWA test).

\section{Conclusion}

The study identified that nurses working in ICUs of Tertiary care hospitals in the region have average knowledge of ET suctioning, though their practice was good. Still the authorities of theses hospital may improve their knowledge and practice by arranging special sessions, workshops and training for ICU Nurses on the stated topic to improving their knowledge and practice regarding ET suctioning, it will prevent patients from getting infections and other complications. Development and implementation of policies is also needed.

\section{References}

1. Negro A, Ranzani R, Villa M, Manara D (2014) Survey of Italian intensive care unit nurses' knowledge about endotracheal suctioning guidelines. Intensive Crit Care Nurs 30(6): 339-345.
2. Day T, Iles N, Griffiths P (2009) Effect of performance feedback on tracheal suctioning knowledge and skills: randomized controlled trial. J Adv Nurs 65(7): 1423-1431.

3. Day T, Farnell S, Haynes S, Wainwright S, Wilson-Barnett J (2002) Tracheal suctioning: an exploration of nurses' knowledge and competence in acute and high dependency ward areas. J Adv Nurs 39(1): 35-45.

4. Day T, Wainwright SP, Wilson-Barnett J (2001) An evaluation of a teaching intervention to improve the practice of endotracheal suctioning in intensive care units. J Clin Nurs 10(5): 682-696.

5. Kelleher S, Andrews T (2008) An observational study on the opensystem endotracheal suctioning practices of critical care nurses. J Clin Nurs 17(3): 360-369.

6. Oliveira Matias Ferreira A, Rosa Silvino Z, Pompeu Christovam B, Vala(Crio Machado de Lima D (2013) Endotracheal Suctioning in Intensive Care Unit: an Integrative Review. Journal of Nursing 7(7): 4910-4917.

7. Elbokhary R, Osama A, AL-khader M (2015) Knowledge and Practice of ICU Nurses Regarding Endotracheal Suctioning for Mechanically Ventilated Patients in Khartoum Teaching Hospital. American Journal of Clinical Neurology and Neurosurgery 1(2): 92-98.

8. Bhanu PB, Limi ED, Indira S (2016) Knowledge regarding ET suctioning among staff nurses and student nurses in $\mathrm{NMCH}$, Nellore. International Journal of Applied Research 2(6): 150-152.

9. Khimani R, Ali F, Rattani S, Awan S (2015) Practices of Tracheal Suctioning Technique among Health Care Professionals: Literature Review. International Journal of Nursing Education 7(1): 179-183.

10. Nishamol YN (2011) A study to assess the knowledge and practice of endotracheal suctioning among neuronurses SCTISMT.

\section{Your next submission with Juniper Publishers will reach you the below assets}

- Quality Editorial service

- Swift Peer Review

- Reprints availability

- E-prints Service

- Manuscript Podcast for convenient understanding

- Global attainment for your research

- Manuscript accessibility in different formats

( Pdf, E-pub, Full Text, Audio)

- Unceasing customer service

Track the below URL for one-step submission https://juniperpublishers.com/online-submission.php 